\title{
Research on Hearing System of Civil Prosecutorial Supervision
}

\author{
Dayang Li \\ The Supreme People's Procuratorate \\ Beijing, China
}

\author{
Yang Xue \\ Shandong Labor and Personnel Dispute Arbitration Court \\ Ji'nan, China
}

\begin{abstract}
This paper centers on the hearing system in civil procuratorial work, it is an important procedural means for procuratorial organs to implement legal supervision, which can effectively guarantee them to find out facts of cases and improve the accuracy of prosecutorial supervision. Therefore, it plays an important role in strengthening the rigidity of civil procuratorial supervision, protecting rights of parties and enhancing people's sense of acquisition in the rule of law. At this stage, hearing system of civil prosecutorial supervision exists obvious shortcomings, such as the low rate of application and the undesirable results effect. Moreover, the system construction of hearing in civil procuratorial work is too general and many regulations can't meet the new requirements of current cases. In order to improve the construction of civil procuratorial hearing system, we must take various ways such as standardizing the types of cases, strengthening the judicial practice of the hearing system and enhancing the cohesion of related systems, so as to produce a maximized effect of hearing system.
\end{abstract}

Keywords-civil procuratorial; litigation supervision; hearing system

\section{INTRODUCTION}

Rules for Supervision [Rules for Supervision of Civil Procedure (Trial Implementation)] that the Supreme People's Procuratorate promulgated and implemented in September, 2013, among which articles 57 to 64 stipulated the hearing system of the civil procuratorial work. However, in the practice of civil procuratorial cases, due to the less unified process of handling cases, the unspecified applicable conditions and undefined purpose of the system, hearing system could be so seldom applied by the procuratorial organs that it always shows a certain degree of vacancy. Even the procuratorial organs which have more application of the hearing system are still in the exploratory stag and have not given full role of the hearing system. In this regard, by the way of analysing the reasons for the low proportion and poor effect of the hearing system applying to civil procuratorial supervision and putting forward relevant suggestions on this basis can provide some reference for the development of the civil procuratorial hearing system.

\section{Main Problems in the Hearing System of CiviL PROCURATORIAL SUPERVISION}

\section{A. Few Cases Applied to Hearing System}

According to relevant data, procuratorial organs had handled 115,700 cases of civil procuratorial supervision nationwide from 2017 to April 2019. However, only 1450 cases were applied to the hearing system, accounting for only $1.26 \%$. The proportion of cases applied to hearing system was of great low. It has not played a full role, and there were even certain degree of "dormancy" in practice. The low proportion of the application of the hearings also shows that the procuratorial organs did not regard it as a preferred procedure or even as an optional procedure in the process of handling cases. From 2017 to April 2019, only 30 civil procuratorial supervision cases handled by provincial procuratorial organs applied the hearing system. When the Rules for Supervision had not yet made a complete construction of hearing system, it will be more difficult for lower procuratorial organs to promote the application of the hearing system effectively.

From 2017 to April 2019, procuratorial organs of Yunnan province had handled 920 cases applied to hearing system, more than half of the total number (1450 cases) nationwide. In addition, there were 260 applied cases in Shandong, 70 in Jiangsu, 20 in Chongqing, 12 in Jiangxi, 8 in Hainan and 8 in Xinjiang, accounting for $89.5 \%$ of the national total number. Except the above seven provinces and autonomous regions, the other 26 province's procuratorial organs had applied to hearing system only in 152 cases totally, with an average number of 5.85 per province. According to relevant data, there were some provinces applied to hearing system even in no cases during this period. In short, the total number of cases applied to hearing system in each province is very small.

\section{B. Inconsistent Standard for Initiating the Hearings}

The article 57 of the Rules for Supervision had stipulated the conditions for initiating the hearings by "when procuratorate consider it indeed necessary". However, there is no uniform and clear standard to understand "indeed necessary", causing the dilemma of application of hearing system in practice. First of all, there exists a certain range of discretion for initiating the hearings system. The hearing stipulated in the Rules of Supervision is a procedural system 
that can be initiated by the procuratorial organs according to their powers when they consider it is "indeed really necessary". With the only principled description, it has not stipulated what situations could be considered "really necessary" in detail, bringing much uncertainty and excessive discretion to the procuratorial organs when they made judgments. Secondly, procuratorial organs in different regions have different standards for whether to apply the hearings in handling cases. Stipulating the conditions of initiating hearing system in principle is to encourage different procuratorial organs to explore the initiating standards and range according to their practical needs of handling cases. However, due to the unbalanced development of civil procuratorial work in different regions, different attention has been paid. Some procuratorial organs could apply the hearing system actively and do some work to explore and improve it, while others put it on the shelf for reasons of unclear standards. It may lead to a situation that a same procuratorial case could apply to hearings system in city A while city B not, producing different result of the same case. Finally, the hearing system lacks rigidity. On the one hand, the hearing system is not mandatory for the parties. If one party refuses to participate in the hearing procedure, procuratorial organs can't take any force. Since then, the hearing procedure may become a mere formality, failing to achieve the due effect. On the other hand, while hearing system is not the necessary procedure for handling civil procuratorial supervision cases. It is not necessary to start the hearing even if there were considerable disputes over the fact-finding or the application of law and serious social impact. With the problem of insufficient personnel in civil procuratorial departments, the investigators would naturally ignore this system in the spirit of "the less trouble the better", which leads the system gradually marginalized.

\section{Hearing Procedure Needs Further Standardization}

A complete and stable process is essential for an procedure effectively operated so that the parties could have a sufficient procedural expectations. Otherwise, it will be difficult for the parties and other participants to respond effectively and achieve the expected effect without knowing the specific process of the hearing. The Rules for Supervision mainly stipulated the order of speech, evidence and cross-examination of proof in the hearing process, which regulated the procedure in the hearing, but not the preprocedure and post-procedure of the hearing. As for the existing procedure in the hearing, there are no provisions yet on the parties' rights and obligations, the prosecutors' and other participants' question order, which leads to different procedures in the process of applying the hearing system. And the stipulated order of speech, cross-examination of proof is very similar to the civil procedure, which can not conform to the objective and attributes of the civil procuratorial hearing. In addition, the standard for determining the hearing participants is not clear. Although Yunnan Province is the most widely applied hearing system region in China, more than $80 \%$ of their hearings cases had only involved prosecutors with no other social personages invited. There are no clear standard for when to involve NPC deputies and CPPCC members, when to involve the people's supervisors, people's mediators and expert consultants, when to involve the units where the parties belong and residents' committees where they live, etc. What standards should be followed in inviting all kinds of personnel to participate in the hearing? There is no unified standard yet in practice. For cases involving the social workers such as the NPC deputies, CPPCC members, experts and scholars, there is no clear stipulation about how to submit their Opinion and suggestions after the hearing. Otherwise, the connection and application between the hearing system and other systems are not clearly stipulated at present, which can only be relied on the procuratorial organs' exploration in judicial practice.

\section{THE CONCRETE COUNTERMEASURES TO IMPROVE THE HEARING SYSTEM OF CIVIL PROCURATORIAL SUPERVISION CASES}

\section{A. Defining the Conditions for Civil Procuratorial Supervision Cases to Initiate Hearing}

Article 57 of the Rules for Supervision had stipulated the conditions for initiating the hearings by "when People's Procuratorate Consider it indeed necessary". Initiating the hearing procedure according to a doctrine of function and power is an important difference between procuratorial power and judicial power. Otherwise, there may form a "tendency of trial" in procuratorial cases, which would hinder the full exertion of the legal supervision power of procuratorial organs [1]. Under the circumstances that the existing laws and regulations have no compulsory force for the parties to participate in the hearing, only by clarifying the types of cases in which to apply the hearing and the specific content of the "indeed necessary" could bring the hearing system into its full function. We can guide the application of the hearing in the following categories of civil procuratorial supervision cases:

1) Cases are to be made negative decision about the supervision application but petition pressure would emerge: Due to the pressure of petition, in some cases of civil procuratorial supervision, procuratorial organs are usually forced to put forward suggestions of protest or retrial. It is not only an imprecise supervision for civil case, but also greatly reduces the quality of supervision and gradually becomes ineffective supervision. For such cases, it is necessary to initiate hearing. The open hearing procedure would affords an opportunity for parties to express their opinions and provide a surroundings for the prosecutors and hearing participants to interpret the law and reasoning. It would facilitate to get the conclusion of the cases and resolve the contradictions of complaints and petitions.

2) Complex cases or great controversy in fact determination or law application involved: In these cases, procuratorial organs are unable to make accurate judgments or the judgments may cause great controversy that they can only handle it by means of written review and inquiry of the parties. In order to clarify the facts of the case, holding the hearings would allow the parties to fully express their opinions. At the same time, with the help of experts, 
- Announce the names and duties of the participants in the hearing and ask the parties whether to apply for withdrawal.

- The host briefly introduces the trial process and explains the new found facts and the procuratorial organs' opinions to the parties.

- The parties express their views on the procuratorial organs' opinions.

- The procuratorial organs, applicants and other parties give evidence, and the applicants and other parties cross-examine the evidence in turn.

- The prosecutors and participants question the parties.

- The parties conduct a debate.

- Try to organize reconciliation during the hearing.

- Check the record and sign it.

By institutionalizing the procedure of hearing, we can further standardize the record of hearing, making it equal with the record of court trial to enhance the legal effect. At the end stage, it should be handled differently according to the specific circumstances of the case and the connection with other systems. But the most important thing is that after the hearing meeting, the participants should express their opinions orally or in written form which could provide reference for the procuratorial organs.

\section{Making Good Cooperation with Other Systems}

System cooperation mainly includes the cooperation with expert consultation and demonstration system and procuratorial reconciliation system. Expert consultation and demonstration system is same as the hearing system that they are both based on the "outer brain" and it would lead the participants repeat their participation. Therefore, in order to ensure the effectiveness of the implementation of the two systems, give full play to their advantages and save judicial resources, we must make them cooperated well with other systems. When the case is considered highly controversial or necessary to lodge a protect by prosecutors, it is feasible to wrap up the hearings and expert consultation and demonstration meetings, in other words, organize them both at the same time. By strengthening the connection and cooperation, we can fully guarantee the experts' personal experience in reviewing case, ensure their opinions and enhance the accuracy of procuratorial supervision.

Procuratorial reconciliation belongs to the category of judicial reconciliation. It adjusts the substantive rights and obligations of the parties decided in the effective judgment of the court through the parties' consensual settlement of their disputes [5]. Civil procuratorial supervision cases accepted by procuratorial organs mostly act out deep contradictions between the parties because that the court has not settled disputes after judgment ultimately, thus they apply for procuratorial supervision. The hearing procedure organized and implemented in the procuratorial supervision is more flexible and participatory than the court's trial and mediation procedures, and the ways of closing cases would 
be more diversified. In the future, procuratorial reconciliation can be regarded as the legal reason for suspending the review procedure of civil procuratorial supervision cases and the parties can be urged to implement the reconciliation agreement through the specific procedure design. It will be greatly helpful to maximize the effectiveness of the hearing system and realize the two-way care of precise supervision and case closure.

\section{CONCLUSION}

Civil procuratorial hearing is a very important system for procuratorial organs to handle civil procuratorial supervision cases. It is also an important means for procuratorial organs to exercise the power of investigation and verification, make good use of the "outer brain" and achieve precise supervision. The work of the Supreme Procuratorate in revising the Rules for Supervision should further improve the civil procuratorial hearing system and related supporting systems as to give full play to the due role of the hearing system. However, in order to make the hearing system play a real role, in addition to the improvement of the system, the procuratorial organs need to recognize the advantages of the hearing system and apply it in practices actively. In this way, thus we can improve the quality of handling civil procuratorial cases.

\section{REFERENCES}

[1] Zhang Weiping, "Research on Implementation Strategies of Procuratorial Supervision in Civil Procedure," Politics and Law Forum, No. 1, 2015.

[2] Zhang Changhui, "Judicial Hearing: The Value of Mass Participation and Its Operation," Journal of Politics and Law, No. 4, 2017.

[3] Qiu Lianggong, "Lectures on Oral Civil Procedure Law (Notebook 2017), " Yuanzhao Publishing Co., Ltd. 2017, PP. 109-110.

[4] Tang Li and Gu Jiajie, "Integration of Examination and Inspection: On the Border of Civil Procedure Supervision," Xuehai, No. 4, 2015.

[5] Tang Weijian, "Research on Civil Procuratorial Jurisprudence," China Procuratorial Publishing House, 2014, pp. 213-216. 